\title{
Enterobactérias produtoras de ESBL isoladas de uroculturas de pacientes
}

\section{ambulatoriais}

\author{
ESBL producing enterobacteria isolated from outpatients urocultures \\ Enterobacterias productoras de BLEE aisladas de urocultivos de pacientes ambulatorios
}

Recebido: 02/05/2021 | Revisado: 11/05/2021 | Aceito: 16/05/2021 | Publicado: 03/06/2021

Geziella Aurea Aparecida Damasceno Souza

ORCID: https://orcid.org/0000-0002-7130-3776

Universidade Estadual de Montes Claros, Brasil

E-mail: geziella.ufmg@gmail.com

Karina Andrade de Prince

ORCID: https://orcid.org/0000-0001-8231-852X

Centro Universitário Funorte, Brasil

E-mail: karina.prince@bol.com.br

Lorena Aguilar Xavier

ORCID: https://orcid.org/0000-0002-9006-3229

Universidade Estadual de Montes Claros, Brasil

E-mail: lorenaaguilarx@gmail.com

Denise Cardoso Oliveira

ORCID: https://orcid.org/0000-0002-4616-8103 Laboratório Siper, Brasil

E-mail: deniseoliveira424@yahoo.com.br

Daniella Mendes Alves

ORCID: https://orcid.org/0000-0003-1852-5975 Laboratório Siper, Brasil

E-mail: mendesdaniella51@gmail.com

Flávia Mendes Tourinho de Paula

ORCID: https://orcid.org/0000-0002-3625-2520

Centro Universitário Funorte, Brasil

E-mail: flaviatourinho@yahoo.com.br

Juliana Beatriz Lima Cardoso

ORCID: https://orcid.org/0000-0003-2832-6910

Universidade Estadual de Montes Claros, Brasil

E-mail: julianablc@yahoo.com.br

Marina Ramos Costa

ORCID: https://orcid.org/0000-0003-0238-2498

Universidade Federal do Estado do Rio de Janeiro, Brasil

E-mail: marina.ramoscosta@yahoo.com

Lúcia Maria Garcia

ORCID: https://orcid.org/0000-0001-5719-2793

Laboratório Siper, Brasil

E-mail: luc.garcia@yahoo.com.br

Luçandra Ramos Espirito Santo

ORCID: https://orcid.org/0000-0003-0588-6149

Universidade Estadual de Montes Claros, Brasil

E-mail: la_lu_joao@ hotmail.com

\section{Resumo}

O mecanismo de resistência por produção de betalactamases de espectro ampliado (ESBL) vem sendo cada vez mais frequente em saúde pública, tanto no ambiente hospitalar como na comunidade. O objetivo deste estudo foi analisar os casos ocorridos de ESBL em enterobactérias isoladas de uroculturas de pacientes ambulatoriais. Trata-se de um estudo quantitativo, descritivo de delineamento transversal, do tipo documental retrospectivo. Os dados foram coletados a partir dos registros de uroculturas de pacientes comunitários atendidos em um Laboratório de Análises da rede privada, localizado em Montes Claros, Minas Gerais, no período de outubro de 2016 a setembro de 2017. Foram analisados 6.248 registros de uroculturas, sendo 15,7\% $(\mathrm{n}=984)$ positivas. Dentre as positivas, 79,4\% $(\mathrm{n}=781)$ eram enterobactérias e $4,5 \%$ dessas $(n=35)$ produtoras de ESBL. Entre os produtores de ESBL, as espécies mais prevalentes foram Escherichia coli $(68,6 \% / \mathrm{n}=24)$, e Klebsiella pneumoniae $(25,7 \% / \mathrm{n}=9)$. Analisando o perfil de resistência aos antimicrobianos dos ESBL, verifica-se que $100 \%$ são resistentes a todas as cefalosporinas. Observou-se também um percentual significativo de cepas resistentes a antibióticos com inibidores de betalactamases $(31,4 \%)$, a quinolonas $(71,4 \%)$ e a sulfametoxazol/timetoprima $(71,4 \%)$. Os isolados de Klebsiella pneumoniae apresentaram uma relação 
significativa com 3, 76 maior chance $(\mathrm{p}<0,0008)$ de serem produtores de ESBL. Este estudo mostra a resistência bacteriana quanto a produção de ESBL presente em patógenos comunitários, fora do ambiente hospitalar.

Palavras-chave: Betalactamases; Infecções urinárias; Infecções comunitárias adquiridas; Resistência a múltiplos medicamentos; Klebsiella pneumoniae.

\begin{abstract}
The resistance mechanism due to the production of broad-spectrum beta-lactamases (ESBL) has been increasingly common in public health, both in hospital and in community. The objective of this study was to analyze the cases of ESBL in enterobacteria isolated from outpatients urine cultures. This is a quantitative, descriptive cross-sectional study, retrospective documentary type. Data were collected from the uroculture records of community patients treated at a private laboratory of Analysis, located in Montes Claros, Minas Gerais, from October 2016 to September 2017. There were 6,248 uroculture reports analyzed, wich $15.7 \%(n=984)$ were positive. Among the positive ones, $79.4 \%$ $(\mathrm{n}=781)$ were enterobacteria and $4.5 \%$ of these $(\mathrm{n}=35)$ are producing ESBL. Among ESBL producers, the most prevalent species were Escherichia coli $(68.6 \% / \mathrm{n}=24)$, and Klebsiella pneumoniae $25.7 \% / \mathrm{n}=9)$. Analyzing ESBL antimicrobial resistance profile, it appears that $100 \%$ are resistant to all cephalosporins. There was also a significant percentage of strains resistant to antibiotics with beta-lactamases inhibitors (31.4\%), quinolones (71.4\%) and sulfamethoxazole/timetoprime (71.4\%). The Klebsiella pneumoniae isolates showed a significant relationship with 3.76 greater chance $(\mathrm{p}<0.0008)$ of being ESBL producers. This study shows bacterial resistance regarding the production of ESBL presents in community pathogens, outside the hospital environment.
\end{abstract}

Keywords: Beta-lactamases; Urinary tract infections; Community-acquired infections; Multidrug resistance; Klebsiella pneumoniae.

\title{
Resumen
}

El mecanismo de resistencia debido a la producción de betalactamasas de amplio espectro (BLEE) ha sido cada vez más común en la salud pública, tanto en el hospital como en la comunidad. El objetivo de este estudio fue analizar los casos de BLEE en enterobacterias aisladas de urocultivos de pacientes ambulatorios. Se trata de un estudio cuantitativo, descriptivo, transversal, de tipo documental retrospectivo. Los datos fueron recolectados de los registros de urocultivo de pacientes comunitarios atendidos en un laboratorio privado de Análisis, ubicado en Montes Claros, Minas Gerais, desde octubre de 2016 a septiembre de 2017. Se analizaron 6.248 registros de urocultivo, siendo $15.7 \%$ $(\mathrm{n}=984)$ positivos. Entre las positivas, el 79,4\% $(\mathrm{n}=781)$ eran enterobacterias y el 4,5\% de estas $(\mathrm{n}=35)$ productoras de BLEE. Entre los productores de BLEE, las especies más prevalentes fueron Escherichia coli $(68,6 \% / \mathrm{n}$ = 24) y Klebsiella pneumoniae $(25,7 \% / \mathrm{n}=9)$. Al analizar el perfil de resistencia a los antimicrobianos BLEE, parece que el $100 \%$ son resistentes a todas las cefalosporinas. También hubo un porcentaje significativo de cepas resistentes a antibióticos con inhibidores de betalactamasas $(31,4 \%)$, quinolonas $(71,4 \%)$ y sulfametoxazol/timetoprime $(71,4 \%)$. Los aislados de Klebsiella pneumoniae tuvieron una relación significativa con una probabilidad 3.76 mayor (p $<0,0008$ ) de ser productores de BLEE. Este estudio muestra la resistencia bacteriana a la producción de BLEE presentes en patógenos comunitarios, fuera del ámbito hospitalario.

Palabras clave: Beta-lactamasas; Infecciones urinarias; Infecciones comunitarias adquiridas; Resistencia a múltiples medicamentos; Klebsiella pneumoniae.

\section{Introdução}

O mecanismo de resistência por produção de betalactamases de espectro ampliado (ESBL) vem sendo frequentemente relatado em saúde pública, tanto no ambiente hospitalar como na comunidade, no meio ambiente e nos alimentos (Broussier, Haoré, Berjamy, Bertrand, \& Slekovec, 2019; Kurittu, et al., 2021). Em hospitais, ela tem sido citada como uma das principais causas de múltipla droga resistência, sendo comum nesse ambiente, de modo que internação a longo prazo é considerada fator de risco significativo para sua infecção (Talan, et al., 2021).

Mutações em genes bacterianos permitem o aumento do espectro das $\beta$-lactamases com a produção das ESBL. Estes genes podem estar localizados em plasmídeos bacterianos e atualmente já estão disseminados pelo mundo. A habilidade de produção de ESBL pode ser transmitida de uma bactéria a outra através da transferência de material genético por conjugação e também por transformação bacteriana (Hoek, et al., 2020). As ESBL são frequentemente produzidas por Escherichia. coli e Klebsiella spp., os patógenos mais comuns da Infecção do trato urinário (Agegnehu, Worku, Nigussie, \& Tadesse, 2020).

Infecções do Trato Urinário (ITU) por bactérias produtoras de ESBL são um problema emergente em diversas partes do mundo. Arcilla et al. (2020) reportaram uma prevalência de 6,1\% em viajantes da Alemanha. Esses viajantes podem carrear os microrganismos e suas formas de resistência para outros lugares e até mesmo para o mundo inteiro. A tendência é que haja 
um aumento de ITU, o que pode acarretar falha no tratamento empírico. Nos estudos de Carvalho et al. (2021), parte significante dos focos de infecção que levam a sepse são relacionadas ao trato urinário.

A antibioticoterapia empírica no caso de ITU ainda ocorre rotineiramente na prática médica. Às vezes, para não negligenciar o paciente em estado grave, o início do tratamento se faz necessário antes do resultado dos exames laboratoriais (Agegnehu, et al., 2020). No entanto, o uso indiscriminado ou abusivo de antibióticos proporciona uma pressão seletiva sobre os microrganismos o que pode causar sérias alterações na microbiota normal, o aumento da resistência microbiana e diminuir a eficácia dos tratamentos. Arcilla et al. (2020) e Talan et al. (2021) consideram o uso prolongado de antibióticos como fator de risco para o acometimento de infecção por Enterobacteriaceae produtora de ESBL.

A resistência bacteriana é um desafio para o controle de infecções relacionadas a saúde (Alhmidi, et al., 2020) e acarreta impacto na morbidade e mortalidade, maior tempo de internação, gastos com procedimentos diagnósticos e terapêuticos. Sua ocorrência pode ser favorecida devido a gravidade do paciente, instabilidade clínica, dentre outros fatores. É um problema crescente no âmbito da saúde pública no que se refere às doenças transmissíveis (Peters, Dulon, Nienhaus, \& Schablon, 2019).

Diante do exposto, é relevante conhecer o perfil de resistência e sensibilidade antimicrobiana atual e demais fatores relacionados aos microrganismos ESBL positivos, o que contribuiria com evidências para a prática clínica para uma melhor tomada de decisões. Com essa perspectiva, o objetivo do presente estudo visou conhecer os casos ocorridos de ESBL em enterobactérias isoladas de uroculturas de pacientes ambulatoriais, relacionando às variáveis sexo, faixa etária, além da avaliação da sensibilidade/resistência de antimicrobianos a fim de contribuir para atualização de protocolos, além de contribuir para o uso racional de antibióticos na saúde pública.

\section{Metodologia}

Trata-se de um estudo quantitativo, descritivo de delineamento transversal, do tipo documental retrospectivo. Os dados foram coletados a partir dos registros de uroculturas de pacientes comunitários atendidos em um Laboratório de Análises da rede privada, localizado no município de Montes Claros, Minas Gerais, no período de outubro de 2016 a setembro de 2017.

O município de Montes Claros, encontra-se localizado na mesorregião norte do estado de Minas Gerais, distando cerca de $422 \mathrm{Km}$ da capital (Belo Horizonte). Ocupa uma área de 3.589,811 km², com uma densidade demográfica de 101,41 hab $/ \mathrm{km}^{2}$. A cidade conta com uma população residente estimada de 413.487 habitantes, de acordo com o Instituto Brasileiro de Geografia e Estatística [IBGE] (2020).

O universo da pesquisa compreendeu 6.248 registros de uroculturas de pacientes atendidos no laboratório, no referido período. As variáveis consideradas no estudo foram retiradas dos registros de atendimento dos pacientes, realizado pela equipe multidisciplinar do laboratório. Foram constituídas como variáveis independentes: sexo, faixa etária, regime do atendimento (público ou particular), bactéria isolada e perfil de susceptibilidade aos antimicrobianos.

Quanto aos procedimentos laboratoriais, a coleta de urina foi realizada pelos pacientes após orientação de profissionais capacitados pela empresa, sendo colhido o segundo jato urinário com prévia higienização da região urogenital. Foi recomendado, preferencialmente, a primeira urina da manhã ou retenção por, pelo menos, quatro horas. Com esse procedimento pode-se melhorar a concentração bacteriana da amostra, melhorando a sensibilidade e especificidade da análise laboratorial.

As amostras recebidas foram conferidas quanto ao nome e dados pessoais do paciente, recebendo um número de registro e sendo encaminhadas para análise, sendo permitido permanecer por no máximo duas horas em temperatura ambiente e 24 horas sob refrigeração, para evitar crescimento bacteriano e interferir nas análises microbiológicas apresentadas. 
Quanto a análise, $1 \mu \mathrm{L}$ de urina foi semeado nos ágares MacConkey e CLED e incubados em estufa microbiológica a $35^{\circ} \mathrm{C}$ durante 24 a 48 horas para aguardar crescimento microbiano (Agegnehu, et al., 2020). Na interpretação do crescimento microbiológico foram utilizados os seguintes critérios: tipo e qualidade do material biológico; número obtido na contagem de colônias; presença de leucócitos no sedimento urinário; sintomatologia clínica do paciente. Em geral, considera-se provável contaminação crescimento até $10.000 \mathrm{UFC} / \mathrm{mL}$ e, provável infecção, crescimento a partir de $100.000 \mathrm{UFC} / \mathrm{mL}$. Os valores entre $10.000 \mathrm{UFC} / \mathrm{mL}$ e $100.000 \mathrm{UFC} / \mathrm{mL}$ podem apresentar tanto contaminação, como colonização ou infecção verdadeira.

Havendo crescimento significativo, cada microrganismo foi isolado, identificado e testado quanto a sensibilidade aos antimicrobianos. Para identificação, utilizou-se a coloração de Gram, meios de cultura diferenciais e provas de identificação fenotípica, como testes bioquímicos e produção de enzimas, conforme estabelecido no período pelo Clinical Laboratory Standards Institute [CLSI] (2015) e Agência Nacional de Vigilância Sanitária [ANVISA] (2013).

A sensibilidade/resistência desses antibióticos foi definida pelo método de disco difusão, através da medida do halo formado que representa a inibição do crescimento microbiano. O microrganismo poderá apresentar sensibilidade total, sensibilidade intermediária ou resistência a cada antibiótico testado de acordo com a medida do halo em milímetros. Os pontos de corte dos halos de inibição do crescimento bacterianos são padronizados com base nos documentos do CLSI (2015) e ANVISA (2013).

Como critério de identificação para ESBL positivo, utilizou-se como triagem a sensibilidade às cefalosporinas, baseando-se nos seguintes critérios: cefotaxima com halo menor ou igual a vinte e sete milímetros e ceftriaxona com halo menor ou igual a vinte e cinco milímetros. Como confirmatório, realizou-se o teste do disco combinado, segundo Agenehu (2020) e respeitando a normativa vigente durante o período da coleta (CLSI, 2015)

Os resultados foram registrados no banco de dados da instituição e utilizados no presente estudo. A frequência de culturas positivas foi calculada. Sobre as culturas positivas, calculou-se a frequência de infecções causadas por enterobactérias. Dentre as culturas positivas para enterobactérias, o percentual de cepas produtoras de ESBL foi calculado. Os dados das culturas positivas e cepas produtoras de ESBL foram comparados com sexo, faixa etária, regime do atendimento, bactéria isolada e perfil de susceptibilidade aos antimicrobianos.

A análise comparativa entre a presença de ESBL e as diferentes enterobactérias isoladas foi realizada com o teste Exato de Fisher. Para avaliar a relação entre as cepas produtoras de ESBL e as espécies de enterobactérias identificadas, foi utilizada a força de associação estimada pelo Odds Ratio (OR), com intervalo de confiança de 95\% (IC 95\%). A análise estatística foi realizada através do programa estatístico Statistical Package for Social Sciences ${ }^{\circledR}$ (SPSS), versão 21 e p $<0,05$ foi considerado estatisticamente significativo.

Quanto aos preceitos éticos da pesquisa, o projeto foi aprovado pelo Comitê de Ética em pesquisa das Faculdades Unidas do Norte de Minas - FUNORTE/Sociedade Educativa do Brasil-SOEBRAS sob o parecer de número 2.344.456/2017, obedecendo as normas da resolução do conselho nacional de saúde (466/2012), ainda em vigor no que tange pesquisa com seres humanos.

\section{Resultados}

Foram analisadas durante o período de estudo 6.248 registros de uroculturas. O percentual de uroculturas positivas foi de $15,7 \%$ ( $\mathrm{n}=984)$. Dentre as uroculturas positivas, 79,4\% ( $\mathrm{n}=781)$ foram identificadas como enterobactérias e 4,5\% dessas $(\mathrm{n}=35)$ apresentaram teste positivo para produção de ESBL. Analisando os isolados produtores de ESBL, as espécies mais prevalentes foram a Escherichia coli $(68,6 \% / \mathrm{n}=24)$, e a Klebsiella pneumoniae $25,7 \% / \mathrm{n}=9)$ que, juntamente com as demais espécies podem ser observadas na Figura 1. 
Figura 1. Enterobactérias produtoras de ESBL isoladas de uroculturas.

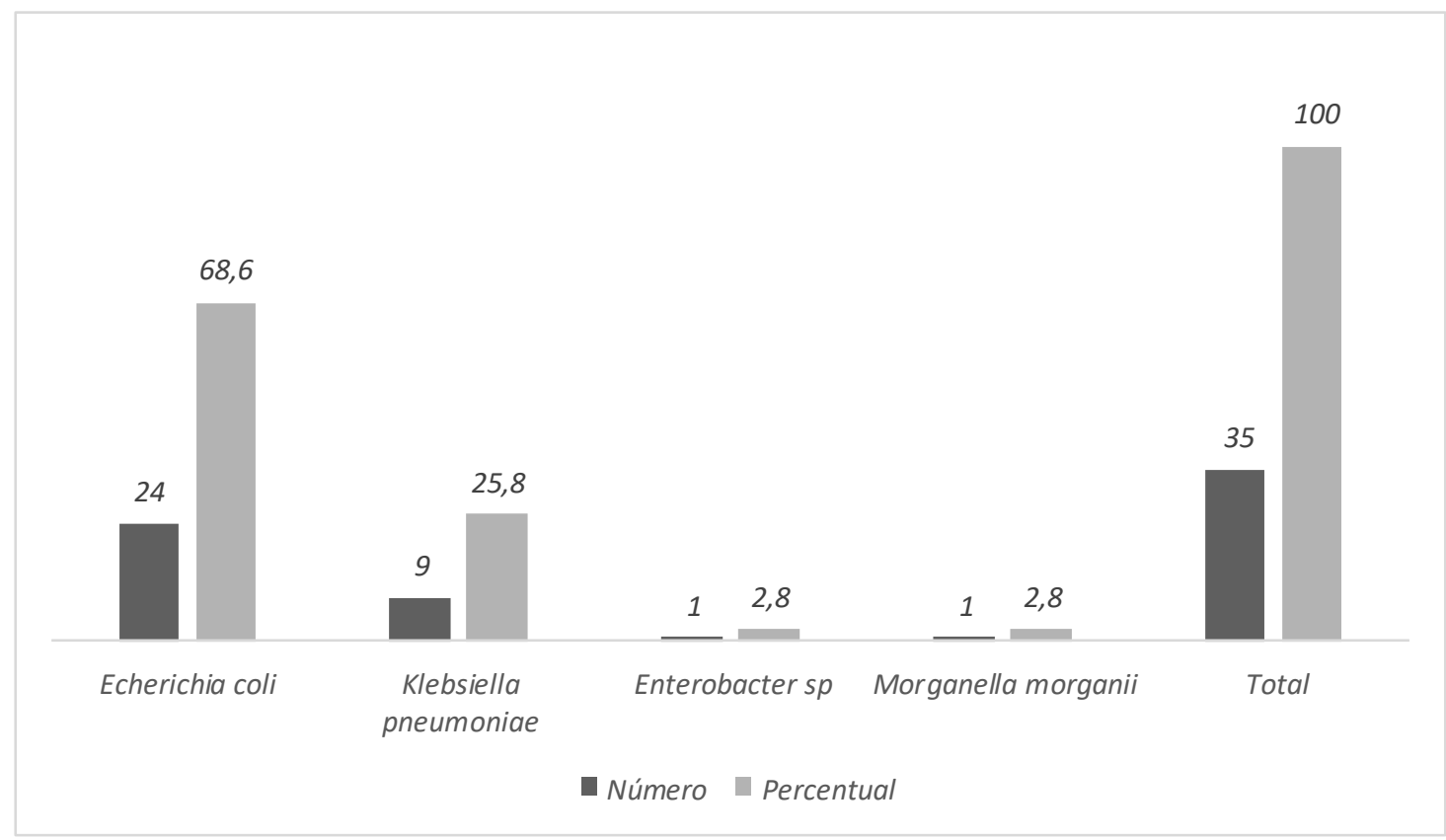

Fonte: Autores (2021).

Do total de uroculturas positivas, $72,2 \%(n=710)$ foram realizadas em regime particular e $27,8 \%(n=274)$ em regime público (SUS).

Quanto ao sexo dos pacientes, 54,3\% ( $\mathrm{n}=19)$ pertenciam ao sexo feminino e 45,7\% ( $\mathrm{n}=16)$ ao sexo masculino. Em relação a faixa etária, a maioria com idade acima de 60 anos $(60 \% / \mathrm{n}=21)$ e com idade entre 20 a 59 anos $(37,1 \% / \mathrm{n}=13)$.

O perfil de resistência aos antimicrobianos dos isolados produtores de ESBL é apresentado na Figura 2. Verifica-se que $100 \%$ são resistentes a todas as cefalosporinas. Observou-se também um percentual significativo de cepas resistentes a antibióticos com inibidores de betalactamases $(31,4 \%)$, a quinolonas $(71,4 \%)$ e a sulfametoxazol/timetoprima $(71,4 \%)$. 
Figura 2. Perfil de resistência dos isolados produtores de ESBL.

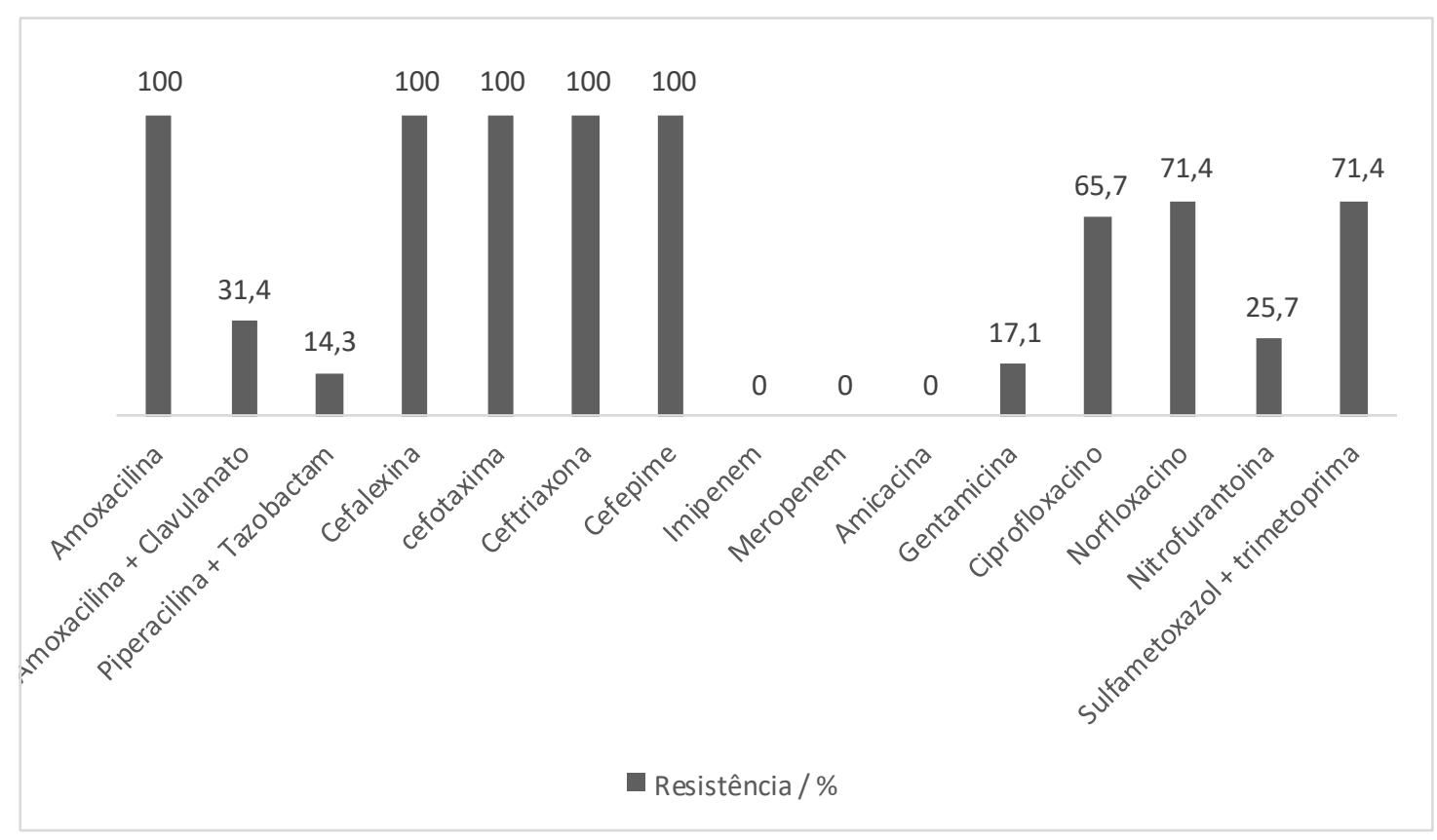

Fonte: Autores (2021).

Entre os isolados ESBL avaliados, somente os de Klebsiella pneumoniae apresentaram relação estatisticamente significativa com a produção de ESBL (p<0,0008) e apresentaram 3,76 vezes uma maior chance de serem produtores de ESBL. Os resultados desta associação podem ser conferidos na Tabela 1.

Tabela 1. Associação entre cepas isoladas de enterobactérias e produção de ESBL.

\begin{tabular}{cc}
\multicolumn{2}{c}{ Variáveis Avaliadas } \\
$(95 \% \mathrm{CI})$ & Odds Ratio \\
\hline Escherichia coli & 1,36 \\
Klebsiella pneumoniae & 3,76 \\
Enterobacter sp. & 1,24 \\
Morganella morganii & 2,51 \\
\multicolumn{2}{c}{ Fonte: Autores (2021). }
\end{tabular}

Fonte: Autores (2021).

\section{Discussão}

A emergência de ESBL em infecções comunitárias têm demonstrado a complexidade envolvendo a disseminação de ESBL em Enterobacteriaceae (Broussier, et al., 2019). No presente estudo foi detectada uma prevalência de 4,5\% de isolados ESBL, obtidos de uroculturas de pacientes comunitários. Peters et al. (2019), em seu trabalho de revisão sistemática que incluiu resultados de 22 outros artigos, reporta um percentual variando entre 2.6 a $48.5 \%$ de patógenos ESBL para infecções ocupacionais em funcionários de hospitais. Deve-se salientar que um percentual esperado para pacientes comunitários deveria ser inferior ao percentual de funcionários de hospitais que constituem linha de frente para este tipo de infecção.

A disseminação de cepas ESBL em pacientes comunitários pode estar relacionada ao uso abusivo de antimicrobianos na produção animal que, de acordo com Wang et al. (2020), tem favorecido a seleção de microrganismos resistentes e feito 
com que esses animais se tornassem reservatório de bactérias EBBL. Kurittu et al. (2021) reporta plasmídios carreadores de genes de betalactamases em E. coli e K. pneumoniae isolados em diversos tipos de alimentos animais e vegetais.

Brito et al. (2020), observa que mesmo dentro dos hospitais, além da vigilância epidemiológica, é necessário medidas sócio educativas para promover o uso racional de antibióticos a fim de minimizar a incidência de cepas bacterianas multidroga resistentes. Talvez essa observação seja pertinente também para a comunidade. Harassim et al (2021) aponta falhas emmuitos casos de terapia empírica que mesmo utilizando antibióticos de amplo espectro, foi necessário trocar o medicamento após resultado do antibiograma.

Analisando os isolados produtores de ESBL apresentados na Figura 1, as espécies mais prevalentes foram a Escherichia coli $(68,6 \% / \mathrm{n}=24)$, e a Klebsiella pneumoniae $25,7 \% / \mathrm{n}=9)$. Esses resultados apresentam números mais elevados que os obtidos por Agegnehu et al. (2020) em crianças na Etiópia, sendo que, dentre as Enterobacteriaceae, a maior frequência foi de E. colli com 44,4\% e K. penumoniae com 27,8\%. Os índices podem, no entanto, variar já que, em idosos na Grécia, Ioannou et al. (2020) encontrou um percentual de 40,5\% para E. coli e 13,7\% para K. pneumoniae, mas, observa-se que em ambos os estudos citados as espécies dos principais patógenos coincidem.

Do total de uroculturas positivas, $72,2 \%(n=710)$ foram realizadas em regime particular e $27,8 \%(n=274)$ em regime público (SUS). Quanto ao maior acometimento de ESBL em pacientes oriundos de instituições particulares, sabe-se que a indução de resistência pode acontecer devido a pressão seletiva de antibióticos e que pacientes com maior poder aquisitivo tem mais acesso a tratamento podendo, portanto, fazer maior uso de antibióticos, da mesma maneira que os pacientes de menor nível socioeconômico frequentemente não concluem o tratamento completo devido à falta de recursos, facilitando a seleção de mutantes.

Quanto ao sexo dos pacientes, $54,3 \%(n=19)$ pertenciam ao sexo feminino e $45,7 \%(n=16)$ ao sexo masculino. Em relação a faixa etária, a maioria com idade acima de 60 anos $(60 \% / n=21)$. Ioannou et al. (2020) encontrou um percentual ainda maior de pacientes do sexo feminino entre para pacientes idosos com infecç̃es do trato urinário, sendo 61,3\%. É normal que mulheres por terem uretra mais curta que homens, estejam mais propensas a desenvolver ITU. Koksal et al. (2019) aponta que idade avançada é um fator de risco para o surgimento de infecções por microrganismos ESBL positivos.

Analisando o perfil de resistência aos antimicrobianos dos isolados produtores de ESBL apresentados na FIgura 2, verifica-se que $100 \%$ são resistentes a todas as cefalosporinas. Percebe-se também um percentual significativo de cepas resistentes a antibióticos com inibidores de betalactamases (31,4\%), a quinolonas $(71,4 \%)$ e a sulfametoxazol/timetoprima (71,4\%). Agegnehu et al. (2020) considerou 96,7\% dos isolados ESBL em seu estudo como multidroga resistentes.

Deve-se observar que houve cepas resistentes a antimicrobianos associados a inibidores de beta-lactamases: amoxilina-ácido clavulânico (31,4\%), piperacilina-tazobactam (14,3\%) e sulfametoxazol-trimetoprim $(71,4 \%)$. Resultados muito superiores para amoxacilina-ácido clavulânico (96,7\%) e sulfametoxazol-trimetropin (96,7\%) estão reportados na literatura em pacientes hospitalizados (Agegnehu et al., 2020). Esses resultados sugerem a presença de outro mecanismo de resistência associado além de ESBL.

A resistência aos betalactâmicos penicilinas (amoxacilina e ampicilina), cefalosporinas (cefalexina, cefotaxima, ceftriaxona), mesmo mantendo a sensibilidade aos cabapenêmicos pode ser justificado pela produção de ESBL, porém, houve também alto percentual de resistência a quinolona (ciprofloxacina), fluorquinolona (norfloxacina) e sulfonamida (sulfatrimetropin) o que reduz as possibilidades de escolha na antibioticoterapia. Araújo e Azevedo (2020) apontam que, no futuro, antibióticos como penicilinas e cefalosporinas podem representar obstáculos para o tratamento de doenças por consequência das betalactamases.

Por outro lado, apesar de se enquadrar nos critérios de multi droga resistência, já que é observada a resistência a dois ou mais fármacos de classes distintas para os quais originalmente as bactérias eram sensíveis, todos os isolados ESBL se 
mostraram sensíveis a pelo menos duas drogas testadas, não sendo, portanto, panresistentes nem extensivamente resistentes. As enterobactérias produtoras de ESBL avaliadas no presente estudo, mostraram-se bastante susceptíveis aos carbapenêmicos e aos aminoglicosídeos testados, podendo esses serem utilizados para o tratamento dos pacientes avaliados. Contudo, vale lembrar que já existem relatos na literatura de cepas resistentes a estas drogas (Aldrazi et al., 2020), o que sugere que o uso desses fármacos deve ser moderado e até mesmo evitado, sempre que possível, para evitar o aumento de cepas multidroga resistentes.

Entre os isolados ESBL avaliados (Tabela 1), somente os de Klebsiella pneumoniae apresentaram relação estatisticamente significativa com a produção de $\operatorname{ESBL}(\mathrm{p}<0,0008)$ e apresentaram 3,76 vezes uma maior chance (odds ratio) de serem produtores de ESBL. Agegnehu et al. (2020) também obtiveram um achado semelhante: dentre os isolados de $K$. pneumoniae, $70 \%$ foram positivos para ESBL, enquanto $30 \%$ foram negativos; já quanto a E. coli, $37,5 \%$ foram ESBL positivos e 62,5\% foram ESBL negativas. Esses achados apontam uma associação entre $K$. pneumoniae e a aquisição de mecanismos de resistência devido a produção de ESBL, indicando a necessidade de estudos posteriores.

Frequentemente, as ESBL são codificadas por genes presentes em elementos genéticos móveis (Hoek, et al., 2020), os quais também carregam genes de resistência a outras classes de antibióticos, de modo que cepas produtoras de ESBL multidroga resistentes são a principal causa de falha terapêutica, levando ao aumento considerável de morbidade por infecções bacterianas.

\section{Conclusão}

Enterobactérias produtoras de ESBL embora representem 4,2\% dos uropatógenos reportados neste estudo possuem potencial de se difundir no ambiente comunitário, onde é mais difícil o controle por parte das pessoas que se comparado com o ambiente hospitalar, onde os pacientes são monitorados por profissionais de saúde. Pacientes idosos ou do sexo feminino estão entre os mais acometidos. Este estudo mostra a necessidade de maior controle epidemiológico de microrganismos patogênicos por parte dos serviços de saúde, o que deve incluir orientações ao paciente ambulatorial. Outros trabalhos devem ser realizados para acompanhar a evolução dos dados e colaborar na adoção de medidas para controle desses microrganismos resistentes.

\section{Referências}

Agegnehu, A., Worku, M., Nigussie, D. \& Tadesse, B. T. (2020). Pediatric Febrile Urinary Tract Infection Caused by ESBL Producing Enterobacteriaceae Species. BioMed research international, 10.1155/2020/6679029.

Agência Nacional de Vigilância Sanitária. (2013). Microbiologia Clínica para o controle de infecção relacionada à assistência à saúde: Módulo 4: Procedimentos laboratoriais: Da requisição do exame à análise microbiológica e laudo final. Ministério da Saúde.

Aldrazi, F. A., Rabaan, A. A., Alsuliman, S. A., Aldrazi, H. A., Alabdalslam, M. J., Alsadiq, S. A., ALhani, H. M.\& Bueid, A. (2020). ESBL expression and antibiotic resistance patterns in a hospital in Saudi Arabia: Do healthcare staff have the whole picture? Journal of Infection and Public Health, 13 (5), 759 766. 10.1016/j.jiph.2019.12.001.

Alhmidi, H., Cadnum, J. L., Koganti, S., Jencson, A. L., BonomoR. A., Wilson, B. M., Mayer, J. M., Samore, M. H. \& Donskey, C. J. (2020). Shedding of multidrug-resistant gram-negative bacilli by colonized patients during procedures and patient care activities. American journal of infection control, 48(11), 1336-1340. 10.1016/j.ajic.2020.06.004.

Arcilla , M. S., Hattem, J. M. V., Bootsma, M. C. J., Genderen, P. J. J. V., Goorhuis, A., Grobusch, M. P., Klaassen, C. H. W., Lashof, A. M. O., Schultsz,C., Stobbering, E. E., Jong, M. D., Penders, J., Verbrug, H. A \& Melles, D. C. (2020). Prevalence and risk factors for carriage of ESBL-producing Enterobacteriaceae in a population of Dutch travellers: A cross-sectional study. Travel medicine and infectious disease, 33 , 101547. 10.1016/j.tmaid.2019.101547.

Araújo, L. L. C. \& Azevedo, F. H. C.(2020). Estudo da enzima beta-lactamase e sua relação com a resistência aos antibióticos. Research, Society and Development, 9 (7), e663974594. 10.33448/rsd-v9i7.4594.

Brito, C.B.S., Correia, K. G., Beerra, J. L., Sousa, J. C., Andrade, S. M., Cunha, M. A., Taminato, R. L \& Oliveira, E. H. (2020). O uso de antibióticos e sua relação com as bactérias multirresistentes em hospitais. Research, Society and Development, 9 (11), e2129119852. 10.33448/rsd-v9i11.9852.

Broussier, M., Haoré, H. G., Berjamy, F. R., Bertrand, X. \& Slekovec, C. (2020). Prevalence, genetic diversity of and factors associated with ESBL-producing Enterobacterales carriage inresidents of French nursing homes. The Journal of hospital infection, vol 104 (4), 469-47510.1016/j.jhin.2019.12.008. 
Carvalho, P. P., Porto, M. J., Barros, J. F., Magalhães, A. S., Nunes, L. S., Silva, I. C., Abreu, I. L. S., Souza, G. N., Rezende Neto, J. M \& Mendes, T. S. (2021). Avaliação de pacientes críticos com suspeita de sepse em um hospital universitário. Research, Society and Development, 10 (3), e39410313570. doi:10.33448/rsd-v10i3.13570.

Clinical Laboratory Standards Institute. (2015). M02-A 12: Performance standards for antimicrobial disk susceptibility tests (12a ed). CLSI.

Harassim, L., Silva, O. L. F., Pinheiro, L. F. S., Santos, E. J. A., Cerdeira, C. D. \& Barros, G. B. S. (2021). Fatores de risco e perfil do uso de antimicrobianos entre pacientes com infecção no trato urinário em uma unidade de terapia intensiva. Research, Society and Development, 10 (3), e43910313516. doi:10.33448/rsd-v10i3.13516.

Hoek, A. H. A. M. V., Dieriks, C., Bosch, T., Schouls, L., Duijkeren, E. V. \& Visser, M. (2020). Transmission of ESBL-producing Escherichia coli between broilers and humans on broiler farms. Journal of Antimicrobial Chemotherapy, 75 (3), 543-549. 10.1093/jac/dkz507.

Instituto Brasileiro de Geografia e Estatística. (2020). Brasil/Minas Gerais/Montes Claros. Recuperado de https://cidades.ibge.gov.br/brasil/mg/montesclaros/panorama.

Ioannou, P., Plexousaki, M., Dimogerontas, K., Aftzi, V., Drougkaki, M., Konidaki, M., Paschalidis, K., Maraki, S. \& Kofteridis, D. P. (2020). Characteristics of urinary tract infections in older patients in a tertiary hospital in Greece. Geriatrics and Gerontology International, 20 (12), 1228-1233. 10.1111/ggi.14080.

Koksal, E., Tulek, N., Sonmezer, M. C., Temocin, F., Bulut, C., Hatipoglu, C., Erdinc, F. S. \& Ertem, G. (2019). Investigation of risk factors for community acquired urinary tract infections caused by extended-spectrum beta-lactamase Escherichia coli and Klebsiella species. Investigative and Clinical Urology, 60 (1), 46-53. doi:10.4111/icu.2019.60.1.46.

Kurittu, P., Khakipoor, B., Aarnio, M., Nykäsenoja, S., Brouwer, M., Myllyniemi, A. L., Vatunem, E. \& Heikinheimo, A. (2021). Plasmid-Borne and Chromosomal ESBL/AmpC Genes in Escherichia coli and Klebsiella pneumoniae in Global Food Products. Frontiers in Microbiology, 12 , Article 592291. doi:10.3389/fmicb.2021.592291.

Peters, C., Dulon, M., Nienhaus, A. \& Schablon, A. (2019). Occupational Infection Risk with Multidrug-Resistant Organisms in Health Personnel-A Systematic Review. International Journal of Environmental Research and Public Health, 16 (11). 10.3390/ijerph16111983.

Resolução $n^{\circ}$ 466, de 12 de dezembro de 2012. Dispõe sobre as diretrizes e normas regulamentadoras de pesquisas envolvendo seres humanos. Diário da República, http://conselho.saude.gov.br/resolucoes/2012/Reso466.pdf.

Talan, D. A., Takhar, S. S., Krishnadasan, A., Mower, W. R., Pallin, D. J., Garg, M., Femling, J., Rothman, R. E., Moore, J. C., Jones, A. E., Lovecchio, F., Jui, J., Steele, M. T., Stubbs, A. M., Chiang, W. K \& Moran, G. J. (2021). Emergence of Extended-Spectrum b-Lactamase Urinary Tract Infections Among Hospitalized Emergency Department Patients in the United States. Annals of Emergency Medicine. 77(1), 32-43. doi:10.1016/j.annemergmed.2020.08.022.

Wang, X. R., Lian, X. L., Su, T. T., Long, T. F., Li, M. Y., Feng, X. Y., Sun, R. Y., Cui, Z. H., Tang, T., Xia, J., Huang, T., Liu, Y. H., Liao, X. P., Fang, L. X. \& Sun, J. (2021). Duck wastes as a potential reservoir of novel antibiotic resistance genes. The Science of the total environment, 771 (1), article144828. 10.1016/j.scitotenv.2020.144828. 